\title{
AMINO ACIDS IN FOWL SEMINAL PLASMA
}

\author{
L. G. CHUBB AND DOREEN M. COOPER \\ Houghton Poultry Research Station, Houghton, Huntingdonshire \\ (Received 10th November 1960, revised 9th February 1962)
}

\begin{abstract}
Summary. The free amino acids occurring in alcoholic extracts of fowl seminal plasma have been examined by filter-paper chromatography. Twenty-three have been detected consistently, and these include several that have not been hitherto reported in the seminal plasma of the domestic fowl. In addition, several unknown ninhydrin-reacting substances have been found. Glutathione and ergothioneine were not detected in the volumes of plasma chromatographed. There was evidence of the presence of glycocyamine and an unknown imidazole compound.
\end{abstract}

\section{INTRODUCTION}

Lake \& McIndoe (1959) reported that about $80 \%$ of the free amino acids found in fowl seminal plasma is accounted for by glutamic acid. They also noted the presence of small amounts of $\alpha$-alanine, aspartic acid, glycine, serine and several unidentified amino acids which yielded dinitrophenyl derivatives. Gassner \& Hopwood (1952) using paper chromatography found the same free amino acids and also histidine and phenylalanine in the seminal plasma of the bull. On the other hand, Larson \& Salisbury (1953) detected seventeen free amino acids in the seminal plasma of the bull, although ten were present only in trace amounts. Jacobsson (1950) and Lundquist (1952) have also reported the presence of fourteen free amino acids in human seminal plasma. In the present investigation, studies have been made with paper chromatography for the identification of the free amino acids in the seminal plasma of the domestic fowl.

\section{MATERIALS AND METHODS}

FOWLS

Five Rhode Island Red cockerels 13 months of age were used in this study. The birds were housed in individual cages and fed the following ration:

$\begin{array}{lrlll}\text { Ground wheat } & 54 & \mathrm{lb} & \text { Limestone flour } 3 \mathrm{lb} \\ \text { Ground barley } & 15 \mathrm{lb} & \text { Bone flour } & 2 \mathrm{lb} \\ \text { Ground oats } & 15 \mathrm{lb} & \text { Salt } & 0.5 \mathrm{lb} \\ \text { White fishmeal } & 5 \mathrm{lb} & & \\ \text { Meat and bonemeal } & 2.5 \mathrm{lb} & \text { Vitamin A } & 4 \text { million i.u./ton } \\ \text { Soyabean meal } & 7.5 \mathrm{lb} & \text { Vitamin D-3 } & 1 \text { million i.u./ton } \\ \text { Dried grassmeal } & 5 \mathrm{lb} & \text { Riboflavin } & 4.48 \mathrm{~g} / \text { ton } \\ \text { Unextracted dried yeast } & 2.5 \mathrm{lb} & & \end{array}$


COLLECTION OF SEMEN

By use of the abdominal massage technique, individual samples of semen from five males were collected over a period of $3 \frac{1}{2}$ months. The semen was collected into the equipment described by Cooper (1955), crushed ice in the flask bringing the temperature to 1 to $2^{\circ} \mathrm{C}$. Samples were collected within 5 to 7 minutes and immediately centrifuged at $2100 \mathrm{~g}$ for $15 \mathrm{~min}$. The seminal plasma was quickly removed and four volumes of $95 \%$ ethanol added. The mixture was gently agitated and then allowed to stand for $30 \mathrm{~min}$ at $0^{\circ} \mathrm{C}$. The precipitated protein was removed by centrifugation at $1500 \mathrm{~g}$ and aliquots of the supernatant aqueous alcoholic extract equivalent to $0.1 \mathrm{ml}, 0.25 \mathrm{ml}$ and $0.5 \mathrm{ml}$ of seminal plasma were taken to dryness at room temperature by means of a hair dryer delivering cold air. The residues were taken up with $0.03 \mathrm{ml}$ of distilled water and applied to the chromatograms. Desalting was found to be unnecessary.

\section{SEPARATION AND IDENTIFICATION OF AMINO ACIDS}

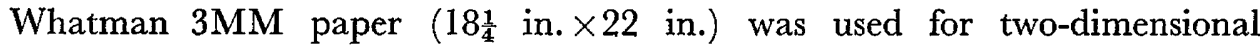
chromatography. Two different solvent systems were used. In the first system, $n$-butanol : acetic acid : water $(60: 15: 25)$ was used in the first dimension with a total length run of $40 \mathrm{~cm}$. After drying, the paper was run in the second dimension for a distance of $35 \mathrm{~cm}$ with water-saturated phenol and a $20 \%$ solution of ammonia (sp. gr. 880) in the tank. This solvent system gave satisfactory separation of all the amino acids present with the exception of methionine +valine and leucine+isoleucine. In the second system, secondary butanol:3\% ammonia $(150: 60)$ was used as the first solvent and secondary butanol:formic acid : water $(150: 30: 20)$ in the second dimension, both with a run of $35 \mathrm{~cm}$. This system separated methionine from valine and the two leucines. The air-dried chromatograms from the first solvent system were washed in acetone to remove the final traces of phenol and together with the dried chromatograms from the second system were sprayed with ninhydrin $(0.2 \%$ in acetone, $\mathrm{w} / \mathrm{v})$. They were heated at $80^{\circ} \mathrm{C}$ for $10 \mathrm{~min}$ and the strength of the spots estimated visually from their size and colour intensity. Hydrogen peroxide oxidation was used to detect the possible presence of cystine (formation of cysteic acid). One-dimensional ascending chromatograms were also run in butanol:acetic acid: water and examined with specific location reagents: proline (isatin:ninhydrin, Kolor \& Roberts, 1957); arginine (Sakaguchi); histidine ( $p$-anisidine); tryptophan and citrulline (Ehrlich) (Smith, 1958). Butanol : formic acid: water $(63: 20: 17)$ was used as an additional developing solvent for the identification of glycocyamine.

The amino acids and other compounds were identified by their $R f$ values compared with those obtained with individual pure substances run simultaneously through the whole chromatographic procedure.

\section{HYDROLYSIS OF EXTRACTS}

In order to hydrolyse any peptides present, the residues from ethanol extracts were heated with $6 \mathrm{~N}$-hydrochloric acid for $16 \mathrm{hr}$ at $100^{\circ} \mathrm{C}$ in a closed glass 
phial. The hydrolysate was taken to dryness in a current of warm air, taken up in water and run on two-way chromatograms.

\section{DETECTION OF THIOL COMPOUNDS}

As cysteine does not form a distinct spot and glutathione runs to nearly the same position as cysteic acid on the two-way chromatograms, the method of Benesch, Benesch, Gutcho \& Laufer (1956) with $n$-ethylmaleimide (NEM) as the location reagent was adopted after one-dimensional chromatograms had

TABLE I

FREE AMINO AGIDS IN THE SEMINAL PLASMA OF THE FOWL

\begin{tabular}{|c|c|}
\hline Amino acid & $\begin{array}{l}\text { Relative amount in } \\
\text { plasma* }\end{array}$ \\
\hline $\begin{array}{l}\text { Glycine } \\
\text { o-Alanine } \\
\text { Serine } \\
\text { Threonine } \\
\text { Valine } \\
\text { Methionine } \\
\text { Tryptophan } \dagger \\
\text { Leucines } \\
\text { Aspartic acid } \\
\text { Glutamic acid } \\
\text { Arginine } \\
\text { Lysine } \\
\text { Histidine } \\
\text { Cystine (as cysteic acid after } \mathrm{H}_{2} \mathrm{O}_{2} \text { oxidation) } \\
\text { Cysteine } \\
\text { Phenylalanine } \\
\text { Tyrosine } \\
\text { Proline } \\
\text { Glutamine } \\
\text { Taurine } \\
\text { Asparagine } \\
\text { Citrulline } \\
\gamma \text {-Aminobutyric acid }\end{array}$ & $\begin{array}{l}++ \\
++ \\
++ \\
++ \\
++ \\
+ \\
+ \\
++ \\
+ \\
++++ \\
+ \\
+ \\
+ \\
+ \\
+ \\
+ \\
+ \\
++ \\
++ \\
++ \\
+ \text { occasionally }\end{array}$ \\
\hline
\end{tabular}

* Relative amount: $+\quad=$ small and slightly dense spot

$++\quad=$ medium and medium dense spot

$\dagger$ Ehrlich reagent.

$+++=$ large and very dense spot

been run. In addition, the chromatographic detection of ergothioneine was carried out by the techniques of Mann \& Leone (1953).

\section{RESULTS}

Chromatographic analysis (Table 1) of seminal plasma from five different cockerels showed that broadly their qualitative pattern of amino acids was similar, and little variation was found to occur over a period of $3 \frac{1}{2}$ months. Glutamic acid was found to be the predominant amino acid present, and $\alpha$-alanine, aspartic acid, glycine, proline, serine, threonine, taurine and asparagine were easily detectable. Analysis of increasing amounts of seminal 
plasma $(0.5 \mathrm{ml})$ revealed the presence of small amounts of glutamine, citrulline, arginine, histidine, phenylalanine, tryptophan, the leucines, lysine, valine, methionine and cysteic acid. Only traces of cystine were present since there was only a small increase in the spot size and intensity of cysteic acid after oxidation. Cysteine was the only thiol compound detected by NEM and both glutathione and ergothioneine were found to be absent from the volumes of seminal plasma analysed. A number of unidentified ninhydrin-reacting spots occasionally appeared. Several additional substances were also found with the different location reagents. Examination of the one-dimensional chromatograms by the Sakaguchi reagent revealed two red spots which were arginine $(R f 0.21)$ and another unknown spot $(R f 0.44)$. This has been identified as glycocyamine. Treatment with $p$-anisidine gave two reddish-brown spots, one being histidine ( $R f 0.25$ ) and the other an unknown of $R f 0.49$. Hydrolysis of the seminal plasma extract resulted in some strengthening of the colour intensities but glutamine, asparagine and cysteic acid disappeared. One spot did, however, appear at the same position as dioxyphenylalanine (DOPA). In two samples a small amount of $\gamma$-aminobutyric acid was detected.

\section{DISCUSSION}

Lake \& McIndoe (1959) in their study of the seminal plasma of Brown Leghorn cockerels found that glutamic acid was the predominant amino acid, and this has been confirmed in the present studies. In addition, the presence of $\alpha$-alanine, aspartic acid, glycine and serine, also found by these workers, has been confirmed. However, a number of additional amino acids and unidentified ninhydrin-reacting substances, hitherto unreported in fowl seminal plasma, have been found and include threonine, valine, the leucines, aspartic acid, arginine, lysine, cystine, phenylalanine, tyrosine and proline. These amino acids have been found in human seminal plasma (Jacobsson, 1950; Lundquist, 1952) and in bovine seminal plasma (Larson \& Salisbury, 1953). The latter workers also reported the presence of histidine, serine, tryptophan and methionine, and these, too, have been found in fowl seminal plasma together with cystine, cysteic acid, glutamine, taurine, asparagine and citrulline. The majority of these amino acids have also been detected in the blood plasma of the fowl (Bell, McIndoe \& Gross, 1959; Chubb, 1959), although their relative concentrations were different.

With regard to the unidentified ninhydrin-reacting compounds, whether DOPA was in fact present or not after acid hydrolysis has not been determined, although it is possible that it may have resulted from the oxidation of tyrosine.

The Sakaguchi positive-reacting substance present in addition to arginine is probably glycocyamine. Although Lake \& McIndoe found the only guanidine base present to be creatine, this is a disubstituted one and does not react with the Sakaguchi reagent; the latter only gives a positive reaction with guanidines of the monosubstituted type (Smith, 1958). The unknown substance was found to run to the same $R f$ as pure glycocyamine in three different solvent systems and its presence in fowl seminal plasma is suggested. Its origin and biochemical role in the seminal plasma has not been determined, but in view 
of the large amount of creatine present, glycocyamine may be involved in its synthesis via the transamidation of glycine from arginine to form glycocyamine and the methylation of the latter to form creatine. Considerably more glycine was present than arginine but the utilization of the latter for glycocyamine synthesis suggests an important role for this amino acid in semen metabolism.

The only thiol compound detected consistently and with certainty was cysteine. Glutathione and ergothioneine were found to be absent although Lorenz (1959) has reported the presence of ergothionine in the seminal plasma of the fowl $(2 \mathrm{mg} / 100 \mathrm{ml})$ as well as small amounts of other unidentified reducing substances. In the present studies, cysteine appeared to be the most important reducing substance. The unknown imidazole reacting with $p$-anisidine and sulphanilic acid has not been identified. The negative result with dichloroquinonechloroimide would eliminate any thiolimidazole and its $R f$ in butanol: acetic acid : water precludes carnosine. It is possibly an imidazole metabolite of histidine although the metabolism of this amino acid by fowl spermatozoa or testicular tissue is not known.

Lorenz \& Tyler (1951) have demonstrated the beneficial effect of glycine and certain proteins on the motile life of fowl spermatozoa, and Lake (1960) reported on the effect of a glutamate-containing saline solution on stored fowl spermatozoa. Cooper \& Rowell (unpublished) have found that the reduction in fertility of fowl semen in a diluent consisting of a mixture of several amino acids was less than that of one containing glycine only and this suggests that further work should be undertaken on the quantitative aspects of the aminoacid composition of fowl seminal plasma and the origin and role of several of the amino acids reported in this study.

\section{ACKNOWLEDGMENTS}

We wish to express our thanks to Dr T. Mann, F.R.s., for his constructive criticism of the manuscript and to Mrs P. Ball for technical assistance.

\section{REFERENGES}

Bell, D. J., McIndoe, W. M. \& Gross, D. (1959) Tissue components of the domestic fowl. 3. The nonprotein nitrogen of plasma and erythrocytes. Biochem. 7. 71, 355.

Benesch, R., Benesch, R. E., Gutcho, M. \& Laufer, L. (1956) New color test for thiols and thiol esters. Science, 124, 981 .

Chuвb, L. G. (1959) Application of paper chromatography to avian pathology. I. The free aminoacids in the blood, urine and body tissues of the normal fowl. Poult. Sci. 38, 668.

Cooper, D. M. (1955) A note on a collection apparatus for avian semen. Vet. Rec. 67, 297.

Gassner, F. X. \& Hopwood, M. L. (1952) Seminal amino-acid and carbohydrate patterns of bulls with normal and abnormal testes function. Proc. Soc. exp. Biol., N.Y. 81, 37.

Jacobsson, L. (1950) Free amino-acids in human semen. Acta physiol. scand. 20, 88.

Kolor, M. G. \& Roberts, H. R. (1957) A new reagent for the detection of hydroxyproline on paper chromatograms. Arch. Biochem. Biophys. 70, 620.

LAKe, P. E. \& MaIndoe, W. M. (1959) The glutamic acid and creatine content of cock seminal plasma. Biochem. 7. 71, 303.

LAke, P. E. (1960) Studies on the dilution and storage of fowl semen. F. Reprod. Fertil. 1, 30.

LARSON, B. L. \& SAlisbury, G. W. (1953) The reactive reducing components of semen. The presence of sulphite in bovine semen. 7 . biol. Chem. 201, 601 . 
Lorenz, F. W. \& Tyler, A. (1951) Extension of motile life span of spermatozoa of the domestic fowl by amino-acids and proteins. Proc. Soc. exp. Biol., N.Y. 78, 57.

Lorenz, F. W. (1959) Reproduction in the domestic fowl: physiology of the male. Reproduction in domestic animals, Vol. II, p. 344. Ed. H. H. Cole and P. T. Cupps. Academic Press, New York.

LundQuIsT, L. (1952) Studies on the biochemistry of human semen. IV. Amino-acids and proteolytic enzymes. Acta physiol. scand. 25, 178.

Mann, T. \& Leone, E. (1953) Studies on the metabolism of semen. 8. Ergothioneine as a normal constituent of boar seminal plasma. Purification and crystallization. Site of formation and function. Biochem. F. 53, 140.

Smrth, I. (1958) Chromatographic Techniques. Heinemann, London. 